
ENGINEERING TECHNOLOGY

James Brown, Indiana University-Purdue University Indianapolis

Richard Pfile, Indiana University-Purdue University Indianapolis 


\section{The Development of a One Credit Ethics course for Engineering Technology}

\section{INTRODUCTION}

There is a high demand in engineering and technology for coursework in engineering ethics due to the ABET requirements which stem from society's changes of culture and core values. ABET "a-k" requirements are driving the necessity for cross-cultural ethical dilemmas to be introduced. Additionally, the global perspective in addressing varying standards for ethics must be understood.

The two goals of this paper will be to describe the course content of a one-credit ethics class and how this course meets the ABET criteria. The course content discussion will include the ideology and methodology behind developing an ethics class that can be applied to most any engineering and technology curriculum. The discussion of the course content will include the syllabus outline, the need for an ethics class and a code of ethics, and how case studies are used. Additionally, there will be a discussion regarding the need for risk and safety awareness, the importance of diversity in the workplace, and the need to be able to identify and avoid sexual harassment in any situation.

The second goal will be to describe how ABET program outcomes (i) and (j) are addressed through this ethics course content.

\section{COURSE CONTENT}

The course content for a one credit ethics course sheds light on the areas that require the greatest concentration of discussion and effort. A sample course schedule can be seen in the syllabus located in the Appendix. The course begins with the discussion of what ethics is in the narrow scope of the American "baseball, apple pie and mom" mentality and deals with issues that are relatively straightforward. This approach addresses ethics from a fundamental moral standpoint and uses case studies surrounding issues such as Ford Pinto's exploding gas tank of the late 1970's and the space shuttle Challenger accident in 1986; both of which were the result of poor corporate ethical choices.

Discussions are also held to identify the necessity for a code of ethics and the role that it plays in the profession. The roles typically include:
- Support
- Deterrence and Discipline
- $\quad$ Public Image
- Status Quo
- $\quad$ Business Interests

The advantages and disadvantages of such a code are also discussed with the main deterrents to a code of ethics being the possibility of a resulting legalistic approach ("I didn't break the code so 
I must be OK") and the idea that having a code is "fostering ethical behavior with a stick rather than a carrot" which is brought out by Fleddermann ${ }^{1}$ on page 21.

The measuring stick used to evaluate if the students are grasping these first fundamental concepts presented is simply a homework assignment. The students are asked questions such as "how are personal ethics and business ethics different?", "What are the roots of your personal ethics?", and "Can an engineer who has become a manager truly ever take off her engineer's hat?"

These fundamental concepts are reinforced by asking the students to look at the space shuttle Challenger ${ }^{3}$ and its demise due to potentially "faulty" decision making in the face of political and budgetary challenges. In this case study, the U.S. congress was unhappy with the delays in the space shuttle project and were evaluating NASA's budget at the time of the Challenger launch. Unusually cold temperatures had the potential to affect an o-ring on a solid rocket booster but there was no definitive quantifiable data available to substantiate the risk of the launch. Consequently, the fatal decision to launch the space shuttle on January 28, 1986 was made, not because the decision makers were confident in the scenario and all of the launch criteria had been met, but because of political pressures. With this illustration the students are able to quickly grasp the gravity of such situations and the seriousness of this subject as it pertains to their upcoming careers.

Subsequent work during the semester is used to build upon this fundamental concept of the need for a code of ethics by introducing base reasoning of ethical issues and the origins of ethical thought. A significant portion of the discussions involve how differing cultures view issues and how they can be fundamentally (and sometimes drastically) different than the "American norm". Areas of discussion range from the economically under-privileged to economic superpowers. These discussions are then broadened to include the differences brought out by the varying world's cultural and religious "morals" and how they weigh into the ethical evaluations. Specific examples are brought up such as bribery being the "norm" for businesses in some parts of the world and the limitations placed on businesses by some of the more religiously ruled countries. The students soon discover that the "right thing to do" is sometimes relative at best and may also be very difficult to ascertain.

Using these fundamental foundations, the students are next challenged to explore the roots of their own morals. They are asked to factor their childhood, their parents morals, their culture and any economic advantages they may have had growing up, and inject them visibly into their decision making process to see how they differ from the students around them. This, then, becomes the individual building blocks that each student will have to weigh the case study outcomes against in their personal evaluations and solutions.

The students are asked to evaluate professional issues using case studies that illustrate the challenges faced in the engineering and technology world. The case studies used by the course cross engineering and technology boundaries. These varied studies open the students to the challenges faced in the differing technology areas. These areas include construction, automotive, electrical, mechanical, project management and a host of others. Examples include the construction fiasco of the Denver Airport, the Kansas City Hyatt Regency walkways collapse, the Bhopal chemical plant disaster and a fictitious "Off-shore Chemical Plant Building project ${ }^{8}$ ". 
Giving the students the chance to evaluate cases and then compare to the "real-world" outcomes provides eye-opening glimpses into the challenges and mores of reality.

One such real-world tragedy in the form of a case study that helps the student visualize the differences in both economic advantage and cultural relevance is the Bhopal India Chemical plant disaster. This tragedy involved the low level of safety measures required by the Indian government and the low cost to build and operate such a plant in India. Here the tragic chemical plant accident is evaluated from the perspective of the engineering management, the engineers and workers on site, the economic advantages to the community of Bhopal, and also the view of the homeless families who lived just outside the fence of the plant in their cardboard houses. The students begin to see the massive impact of what may appear to be simple management or cost savings decisions on the business, local community and society as a whole when all of these factors are evaluated using these four moral theories: 1) Utilitarianism - the good of the many over the good of the few, 2) Duty Ethics - we have a duty to protect others rights, 3) Rights Ethics - individuals have the right to not be overlook when it comes to safety, 4) Virtue Ethics moral distinction and goodness.

Ethical problem solving methods comprise a significant portion of the one credit hour class. The students are required to analyze many case studies and also write a five page (minimum) paper that looks at an ethical dilemma of their choice taken from the current events of the past couple of years. The problem solving methods discussed in the class include using utilitarian ethics, duty \& rights ethics, Virtue ethics (described above) and also the PISCO ${ }^{5}$ (Problem, Input,

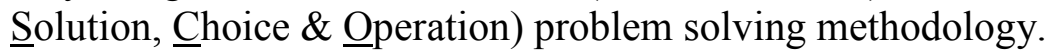

Besides the need for understanding a professions code of ethics and how these ethics play into the world's socio-economic, religious and cultural expectations, the course also spends time discussing issues such as risk and safety, embracing diversity and avoiding sexual harassment.

Risk and safety issues are brought to light by introducing the point that no duty of an engineer is more important than his/her duty to protect the safety and well-being of the public. Along these lines of thought the discussion is brought out that risk and safety are subjective terms and that what may be a risk or an unsafe practice to one person or community may not be for another of a differing background. Thus, five criteria ${ }^{1}$ are defined to ensure there is a quantitative view of risk and safety available to the students. These criteria are: 1) the design must comply with the applicable laws; 2) the design must meet the standard of "accepted engineering practice"; 3 ) alternative designs that are potentially safer must be explored; 4) the engineer must attempt to foresee potential misuses of the product by the consumer and must design to avoid these problems; and 5) once the product is designed, the prototypes and finished devices must be rigorously tested.

Embracing diversity in the view of the global economy is paramount to success for the newly graduated engineer/technologist. A video is shown and discussions subsequent to the video are conducted to bring out the need for not just tolerance but aggressively including the value of diversity into the students' business world as well as their personal lives. Areas of diversity that are addressed are race, religious and cultural differences, mobility/physically challenged individuals' differences, sexual preferences and how to respectfully support these diversities in 
the local workforce. The value of diversity brings greater contribution to the creativity of today's engineers as they must look to the needs outside of their narrowly focused school career to succeed in the global economy.

Finally, avoiding sexual harassment in the workplace (considering an individual as a member of the human race) is addressed. The discussion topics include why sexual harassment is an issue, sexual harassment as discrimination, "quid pro quo" sexual harassment, environmental sexual harassment and ways to prevent sexual harassment. A video ${ }^{7}$ is shown to the students with dramatized examples of what may constitute sexual harassment and in each of the discussion areas a lawyer concludes by addressing how the situation could have been avoided.

All three of these "Other Topics" are included on a test to ensure the students assimilated the presented information in a "useful" way. Average results of these test questions indicate that over $90 \%$ of the students leave this class with a basic understanding of what will be required of them at the first place of employment with regards to safety, diversity and sexual harassment.

\section{MEETING ABET CRITERIA}

The implementation of the ethics course will be of interest to engineering technology programs as part of their plan to address items within ABET "a-k" criteria including: ABET program outcome (i) an ability to understand professional, ethical and social responsibilities and ABET program outcome (j) a respect for diversity and a knowledge of contemporary professional, societal and global issues.

ABET outcome (i) is inherently addressed by the nature of the beginnings of the course with the discussions that revolve around the necessity of ethics in our lives both as individuals and as professionals. Knowledge of the IEEE code of ethics is required as part of the course work and is evaluated by giving the students a "fill in the blank" quiz and asking them to write all 10 canons of the IEEE code of ethics. The necessity of the code of ethics is also reinforced by the case studies that are discussed and evaluated. These case study evaluations come in the form of interactive classroom discussions, homework, and test questions.

ABET outcome (j) is addressed in the cross-cultural nature of both discussions and case study evaluations. Crossing the lines from North America and looking at issues in India, Europe and Mexico force the student to reflect on the great differences that remain between nations. Asking the students to, in effect, "walk a mile in the other person's shoes" gives the students an appreciation and new-found respect for the diversity that exists in today's global economy.

\section{CONCLUSION}

With the demand in technology coursework for engineering ethics to be taught, this paper has sought to introduce the reader to the ease of creating an Engineering Ethics course and some of the required areas for discussion as well as the necessity to stress the global society.

Additionally, the development of such a course allows a department to meet some of the ABET 
"a-k" requirements, with the thought that outcomes (i) \& (j) are not easily achieved in the normal curriculum of an Engineering or Technology program.

\section{APPENDIX - SAMPLE COURSE SCHEDULE}

Week 1 - Ethics Overview

Week 2 - Professionalism and the Codes of Ethics

Week 3 - Understanding Ethical Problems

Week 4 - Ethical Problem Solving

Week 5 - Ethical Problem Solving

Week 6 - Exam \#1

Week 7 - Video Case study \& Discussion

Week 8 - Video Case study \& Discussion

Week 9 - Video Case study \& Discussion

Week 10 - Spring Break

Week 11- Risk \& Safety / Quiz - IEEE Code of Ethics

Week 12 -Sexual Harassment

Week 13 -Diversity

Week 14 -PISCO Problem Solving Model

Week 15 -Case Study using PISCO

Week 16 - Course Review /Final Paper Due

Week 17 - Final Exam

\section{Bibliography}

1. Charles B. Fledderman, Engineering Ethics, Pearson Prentice Hall, Upper Saddle River, NJ., 2004

2. Ethics Center for Engineering and Science, Casewestern University: http:www.onlineethics.org

3. Wikipedia contributors, "Space Shuttle Challenger disaster," Wikipedia, The Free Encyclopedia, http://en.wikipedia.org/w/index.php?title=Space Shuttle_Challenger_disaster\&oldid=42613534.

4. Martin, Mike W., Schinzinger, Roland, Engineering Ethics, McGraw-Hill, New York, NY., 2005

5. deBono, Edward, Six thinking hats., Little, Brown and Company, New York, NY, 1986

6. Video: As Simple as Respect, ATS Media, Chicago, IL., 2004

7. Video: Sexual harassment: is It? or Isn't It?, LearnCom, Bensenville, IL., 1996

8. Video: Incident at Morales, National Institute for Engineering Ethics, Lubbock, TX., 2003 